\title{
Psychological factors of the readiness of teachers to ensure social security in the educational environment
}

\author{
Elena A. Shmeleva*, Pavel A. Kislyakov, Larisa D. Maltseva, Ludmila F. Luneva \\ Ivanovo State University, Ivanovo, Russia
}

${ }^{*}$ Corresponding author. E-mail: konkyrs2012@inbox.ru

The negative sociocultural transformations that are taking place in modern society and the resulting psychological transformation of personality and mode of life strongly require searching for ways of providing social safety to the next generation, with teachers being the implementers of this process. Teachers' professionalism is determined by their willingness to solve personal and socially relevant problems, including the willingness to provide social security for other people, to thwart social risks, and to build constructive interpersonal relationships.

The aim of our research was to reveal and to analyze the psychological factors affecting the readiness of teachers to ensure social security in educational environments.

The environmental factors of social risk have been theoretically characterized. It has been shown that the essential factor in ensuring students' social security is providing a safe social environment in educational institutions; such an environment provides the learners and the teachers with sociopsychological security and psychosocial well-being. The empirical part of our study was devoted to identifying negative social phenomena in the schools in the Ivanovo region (with the help of a questionnaire administered to 700 students) and to identifying the personally and professionally important qualities of the teachers and the subjective psychological factors of their readiness to ensure social security in the educational environment (through interviewing 300 teachers); the administration of the questionnaires and the interviewing were followed by an assessment of their significance (with the help of a questionnaire administered to 140 teachers). Using factor analysis we identified the relevant indicators and grouped them into six factors of the readiness of teachers to ensure a safe educational environment.

Relevant personal and professional qualities of teachers were revealed; these are the subjective factors of the readiness of a teacher to ensure social security in the educational environment: social anticipation, resistance to sociopsychological stress, social tolerance, professional orientation, responsibility, communication skills.

Data were collected in the analytical and experimental studies to determine ways to improve the organization of educational processes in order to ensure the social security of students and society in general. The identified psychological factors, their relative weight, and content must be considered when designing a system for training teachers and developing in them the required personal and professional qualities.

Keywords: social security, educational environment, psychological factors, negative social phenomena in the schools. 


\section{Introduction}

Nowadays the issue of the social security of people and of society has become one of the most pressing problems. The importance of the educational system in opposing negative social processes (drug addiction, alcoholism, youth delinquency, religious and national extremism, homelessness, socially determined diseases) and in forming a healthy and safe mode of life in society is confirmed by the strategic directions of international and national policy. The obvious impossibility of securing a person against all the dangers, threats, and crisis conditions created by progress leads to the necessity of rethinking our current understanding of security. The need for a scientific description of security as part of psychological studies has been noted (Zinchenko, 2011; Zinchenko, Veraksa, \& Leonov, 2011).

The vice president of the Russian Academy of Education, D. Feldshteyn, in revealing the extreme vacuity and vagueness of the modern cultural-historical, political, and psychopedagogical situation, points to the developing resource of psychopedagogical science in human society; the perfection of its account of sociocultural, psychophysiological, and other educational reserves; and the mechanisms and technologies necessary for their utilization (Feldshteyn, 2012).

Studying security as a system is closely connected with the theory of a continual link between personality and the security of a society or organization (Zinchenko, 2011, p. 308). Students often spend more time in an educational establishment than even in their family environment; for this reason, the degree of impact of this microcommunity on the socialization, development, health, and behavior of a child or of a young person is inestimable. Psychological research has shown that the safety of the educational environment is directly connected with the mental health of students and with their progress in school (Glew, Fan, Katon, \& Rivara, 2008; Nansel, Overpeck, Haynie, Ruan, \& Scheldt, 2003).

Nowadays in Russian schools the rate of juvenile violence is increasing; children even record beatings of their classmates on video. According to of mass media «annually thousands of acts of violence are reported to the police; over $60 \%$ of children aged 8 to 17 would agree to take part in violent acts; $6 \%$ of children say they might kill someone if they could benefit from it» (Teenage cruelty in Russia turns into a profitable business, 2007). According to research undertaken in Russia, nearly 40 percent of high school students experience violence in one way or another (Dunne et al., 2009). As a result, a new generation is growing up for whom violence is standard practice. Psychologists have pointed out the seriousness of the consequences of school violence: poor progress in school, problems in relationships with others, low self-esteem, inclination to depression, suicide (Tucker, Finkelhor, Shuttuck, \& Turner, 2013).

Sometimes cases involve unmotivated aggression: when teens are in a state of emotional stress after undergoing psychological trauma, they attack other pupils and teachers, even using firearms. In some studies a tendency toward violence among teens is associated with their level of self-control, social status, prestige, and other characteristics (Tucker et al, 2013). And violence among teens has another side - sometimes children are attacked by teachers. These cases indicate the importance of professional and psychological evaluations of prospective teachers and of the ongoing psychological state of schoolteachers in general. 
As this discussion shows, it's necessary to develop means for ensuring personal social safety in the educational environment. We understand the development of students' social safety as the active responsibility of teachers to create a safe educational environment in order to protect children from social risk and to promote a conscious attitude toward the personal safety of others. This project requires spiritual and moral qualities and skill in revealing, preventing, weakening, and eliminating social dangers and threats that arise in the individual, group, and social and cultural environment. Providing security is among the most important social experiences of a human being. The need for security urges a person to constantly rethink social occurrences as well as to search for adequate ways of overcoming the continuously appearing threats to both physical and spiritual existence (Zinchenko, 2011, p. 309).

Research of security as a sociosystemic phenomenon will determine the interconnected factors that generally provide favorable conditions for safe development (Zinchenko, 2011, p. 314). The social safety of students as a social and psychopedagogical category is determined both outwardly and inwardly and is influenced by psychological factors that are responsible for the achievement of a high level development. Given conditions of radical social change, all the basic elements of a functioning society are revised, both at the state level and at the level of a particular person. Changes occur in the external psychological factors of the formation of personality, such as the functioning of social institutions, the quality of the environment, and the conditions provided by the society for the implementation of human capabilities.

The ability to protect oneself from possible personal threats and to create a secure environment (and a secure relationship with the environment) requires an ideal level of cooperation with the social environment. The human social environment, which aims to guarantee safety, can and should promote the working out of the adaptive behavioral forms of humans in society and should provide a safe behavior pattern that is based on the experience of teaching about relationships. In this case the priority is either the inward nature of the person or the environmental dependence on personal organization. One social environment that promotes the personal safety of people in the process of growing up is the educational institution, which promotes child development and socialization.

The characteristics of the educational institution can be considered environmental factors that determine the psychosocial prosperity (safety) of students. As Maslow figuratively writes (2001, p. 364):

[A] positive environment is one of the first factors of self-actualization and health for the average person. Given the possibility of self-actualization, this environment will withdraw into the shadows like a good- hearted tutor to let one make a choice by oneself in accordance with one's own wishes and demands (retaining one's right to watch that other people's wishes and demands are taken into account).

A natural feeling of safety is one of the basic feelings of a normal person. Children study better when they are safe/happy (Kislyakov, Shmeleva, Karaseva, \& Silaeva, 2014). Some authors say that this psychological prosperity of students should 
become the conceptual basis for educational reform (Noddings, 2003). Gilman and Huebner (2006) associate the psychological prosperity of students with life satisfaction and the ability to control stress; Suldo, Shaffer, and Riley (2008) associate it with high emotional regulation and academic abilities. In Russian and American psychology some methods of determining psychological safety have been developed (Baeva, 2002; Huebner \& Gilman, 2006; Suldo et al., 2008).

Consequently a socially safe educational institution includes the immediate environment of the students, factors of the educational environment and its system of functioning, appropriate conditions for the development of students' psychophysical characteristics (which meet requirements for their safety and physical and mental activity), and also preventive measures against the negative impact of educational risk factors. Nowadays the problem of humanizing the educational environment can be combined with the problem of planning it to be socially safe.

The main social risks that negatively affect the development of educated and healthy children are: macrofactors (social instability and the criminalization of society, social stratification, radicalization of the socioeconomic and sociopolitical subsystems of society); factors in the functioning of social institutions (aggressiveness in the information environment, devaluation of spiritual and moral values, and attraction of the society to asocial behavior); social risks in the educational environment (dehumanization and increase of violence, intensification of the educational process, pedagogical tactics that create stress in students); factors caused by students' staying in a group of social risk (informal youth groups, destructive religious organizations); negative behavioral characteristics of young people (deviant, addictive, victimlike, antisocial) as a consequence of the lessons learned in the socialization process: antisocial norms, values, and worldviews.

Today in real life revelation and analysis of the factors of social dangers are usually carried out intuitively without using appropriate methods, which include quantitative and expert procedures. For instance, teachers may suddenly discover with surprise that some of their students take drugs and are wedded to extremist, suicidal, and other negative views. And sometimes, during several weeks and months, some changes in behavior, signs of an interest in illegal actions, are observed but are not properly evaluated and paid attention to by teachers.

Research shows that about $85 \%$ of teachers are in a state of steady stress, which appears to be the reason for neuroses and somatic illnesses (Tretyakova, 2009; Karaseva \& Babanova, 2010). Increasing neuroemotional stress, psychoemotional tension, and neurotic reactions of teachers have a negative impact on their relations with students. From the health-psychology perspective a normal personality is mentally stable (including being resistant to stress); this stability allows it to support its own reliability and to stand against outside influences, to overcome the resistance of outside conditions, to struggle against hindrances, and finally to achieve goals. Moreover, a teacher, responsible for the safety of students, must be ready to prevent stress in students in extreme situations of social chaos. These requirements speak to the necessity of special psychological preparation for social and extreme (emergency) types of activity. They reveal the need to discover and study the psychological qualities of teachers that will help them provide social security in the educational environment. 


\section{Method}

Our study aimed to identify the psychological factors that influence the readiness of teachers to ensure social security in the school environment.

In the first stage of the study, in order to detect the presence of negative social phenomena in schools, we conducted a survey among students. They were asked to indicate which social evils they had personally experienced or witnessed in school during the previous year (from the date of completion of the questionnaire) (Table 1).

Table 1. Students' reports of the occurrence of negative social phenomena in their educational institutions, $n=700$

\begin{tabular}{|c|c|}
\hline Dangerous situations of a social nature & $\begin{array}{l}\text { Happened at } \\
\text { least once in } \\
\text { previous year }(\%)\end{array}$ \\
\hline Hooliganism (foul language and insults, pushing and beating) & 35 \\
\hline Offering drugs to students & 10 \\
\hline Alcohol consumption by schoolchildren & 46 \\
\hline Information that a student was infected with HIV/AIDS & 9 \\
\hline Appearance of religious sectarians or recruiters & 9 \\
\hline $\begin{array}{l}\text { Harassment by robbers and/or by extorters of money and/or mobile } \\
\text { phones }\end{array}$ & 29 \\
\hline Information regarding a theft that caused discomfort, alarm, fear & 39 \\
\hline Being a victim of a theft & 18 \\
\hline Conflicts and quarrels among students & 50 \\
\hline Conflicts with teachers & 27 \\
\hline $\begin{array}{l}\text { Information regarding displays of nationalism, intolerance by some } \\
\text { students (public demonstration of Nazi attributes or symbols, fomenting } \\
\text { of national discord) }\end{array}$ & 43 \\
\hline $\begin{array}{l}\text { Aggressive actions of so-called informal youth groups (Skinheads, Goths, } \\
\text { Emos, etc.) }\end{array}$ & 6 \\
\hline
\end{tabular}

The questionnaire was devised to obtain information about the frequency of manifestations of certain social risks. The responses were recorded statistically not by their number but in a way that revealed the acceptability of social risk factors in a school. The questionnaire was administered to 700 students in grades 9-11 in 10 schools in the Ivanovo region.

Among the negative social phenomena in the educational environment that appeared to be social risk factors the students reported alcohol abuse among young people (46\%), conflict and quarrels among students (50\%), conflicts with teachers (27\%), manifestations of extremism, nationalism (43\%), and the spread of drugs (10\%). The study also showed that despite the fact that almost all the students (91\%) knew about the leading role of lifestyle in the formation of healthy habits and consequently of readiness to ensure personal safety, only 35\% of them rated their lifestyle as healthy. The factors reported that do not contribute to a healthy lifestyle were poor nutrition (84\%), sedentary lifestyle (25\%), smoking (22\%), alcohol abuse (13\%). Thus, the students were able to assess a number of negative phenomena as social risk factors, as well as the importance to them in a healthy lifestyle (Kislyakov \& Silaeva, 2014). 
In the second stage of the study, in order to discover the important personal and professional traits of educators that serve as subjective psychological factors, we held interviews with educators (teachers, heads of educational institutions, social educators, school psychologists, professors) in the Ivanovo region, Moscow, Saransk, and Sterlitamakh. They were asked to describe the qualities of teachers that enable them to provide for their own defense against social threats and for the defense of students. In all, we interviewed about 300 teaching staff. The results of the poll were shortened and processed, and the following characteristics of the readiness of a teacher to ensure social security were identified:

1. Critical thinking

2. Seeing children as valuable

3. Constant professional self-development

4. Sociability

5. Ability to control one's emotions

6. Restraint

7. Ability to anticipate the course of events

8. Watchfulness

9. Self-assurance

10. Independence

11. Ability to cooperate, to be in contact with other people

12. Ability to keep one's word

13. Sense of duty

14. Ability to correctly determine one's own capabilities

15. Foresight

16. Self-discipline

17. Respect for and acceptance of other people

18. Multiculturalism

19. Outspokenness

20. Tolerance of the views and opinions of other people

These indicators served as a basis for the study of the personal and professional qualities that are necessary for teachers to have if they are to provide social security in educational institutions and to provide students and themselves with sociopsychological security and psychosocial well-being.

In the third stage of the study, in order to establish the value of important personal and professional features that serve as an index of the readiness of teachers to ensure social security, respondents were asked to rate the importance of these features on a 5-point scale:

5 points - "extremely important"

4 points - "very important"

3 points - "fairly important"

2 points - "not very important"

1 point - "not important at all" 
One hundred forty educators took part in this stage. The data from the second stage served as a base for making up the list of features of an educator that are necessary for providing for the personal safety and security of students.

The rating results were processed by factor analysis (analysis of the main components by the Varimax rotation method with Kaiser Normalization) using the standardized software package SPSS 17 . The number of each factor, its name (determined by content), its specific weight, and the teacher characteristics that are included in it are shown in Table 2. The weights of the factors total $61.88 \%$; this is more than half, which is considered an acceptable result. It is a mark of how well the factors represent the set of included characteristics. It reflects the inner validity of the factor structure because it helps explain empirical regularities. When interpreting the factors, we paid attention to the difficulty of tasks (over 0.45). High difficulty of tasks (over 0.5 ) does not cross in factors and does not appear to be common for a few factors.

Table 2. Factors in teachers' readiness to provide social safety, determined by interviews with educators, $n=140$

\begin{tabular}{|c|c|c|c|}
\hline $\begin{array}{l}\text { Number } \\
\text { of factor }\end{array}$ & $\begin{array}{l}\text { Specific } \\
\text { weight of } \\
\text { factor, \% }\end{array}$ & Teacher characteristics & $\begin{array}{l}\text { Factor } \\
\text { name }\end{array}$ \\
\hline 1 & 21.571 & $\begin{array}{l}\text { Watchfulness }(0.766) \\
\text { Ability to anticipate the course of events }(0.760) \\
\text { Foresight }(0.747) \\
\text { Ability to correctly determine one's own capabili- } \\
\text { ties }(0.492) \\
\text { Critical thinking }(0.450)\end{array}$ & $\begin{array}{l}\text { Social } \\
\text { anticipation }\end{array}$ \\
\hline 2 & 14.313 & $\begin{array}{l}\text { Restraint }(0.749) \\
\text { Self-discipline }(0.721) \\
\text { Ability to control one's emotions }(0.468) \\
\text { Self-assurance }(0.570) \\
\text { Sociability }(0.468)\end{array}$ & $\begin{array}{l}\text { Resistance to } \\
\text { sociopsycholo- } \\
\text { gical stress }\end{array}$ \\
\hline 3 & 8.277 & $\begin{array}{l}\text { Tolerance of the views and opinions of other } \\
\text { people }(0.792) \\
\text { Respect for and acceptance of other people }(0.643) \\
\text { Multiculturalism }(0.639) \\
\text { Outspokenness }(0.595)\end{array}$ & Social tolerance \\
\hline 4 & 7.047 & $\begin{array}{l}\text { Constant professional self-development }(0.770) \\
\text { Seeing children as valuable }(0.710)\end{array}$ & $\begin{array}{l}\text { Professional } \\
\text { orientation }\end{array}$ \\
\hline 5 & 5.431 & $\begin{array}{l}\text { Sense of duty }(0.664) \\
\text { Ability to keep one's word }(0.631) \\
\text { Independence }(0.553)\end{array}$ & Responsibility \\
\hline 6 & 5.248 & $\begin{array}{l}\text { Ability to cooperate, to be in contact with other } \\
\text { people }(0.830) \\
\text { Sociability }(-0.502)\end{array}$ & $\begin{array}{l}\text { Communication } \\
\text { skills }\end{array}$ \\
\hline
\end{tabular}




\section{Results and discussion}

Factors were chosen in accordance with the table of factor loadings after rotation; this procedure resulted in a factor structure that is the best available for interpretation at a given ratio of variables and factors; on the basis of this interpretation the key indicators of the readiness of a teacher to ensure social security were marked.

Let's consider the content of the factors shown in Table 2. The first factor, social anticipation, is dominant. This factor can be characterized as an ability to anticipate the course of events, precisely determine one's own capabilities, take stock of an event.

Developed social anticipation helps teachers to predict the results of their plans for providing social safety; to self-adjust the direction of implemented plans; to forecast the rise of dangerous social situations in educational institutions that are created by participants in the educational process; to predict the outcome of emergency situations; and to take action to minimize factors that have a negative influence on students' health.

The second factor, resistance to sociopsychological stress, characterized by restraint, self-discipline, ability to control one's own emotions. Sociability is a part of stress resistance because many teachers consider the ability "to talk," "to build up a constructive dialogue" in stressful situations as a reflection of the ability to selfregulate and to provide urgent psychological assistance in an extreme situation.

The third factor, social tolerance, encompasses sincere respect for and acceptance of other people and their spiritual values. At this time such qualities as ethnic tolerance and personal tolerance are important because teachers in their daily work interact with representatives of different nationalities, different ethnic and social groups, different religious views.

Moreover, tolerance is not the passive acceptance of the opinions, views, and behavior of other people but is an active moral position and is indicative of psychological readiness to have positive interactions with people based on morality and the law.

The characteristics of the fourth factor, professional orientation, bear a direct relation to the direction of the pedagogical profession. Commitment to continuous professional self-development and seeing children as valuable underlie the ability of the teacher to find the personal and social resources necessary to ensure a comfortable learning environment and social situation for the students.

Teachers' formation of a professional orientation in the field of social security is characterized by:

- social and educational values: prioritization of safety, one's own health, and the health and safety of pupils; love for pedagogical work

- personal values and pedagogical activity: assignment of oneself to the field of social security; commitment to professionalism in this field; development of the capacity for self-organization, self-management, and self-education in the field of social security; development of a focus on creative ways of working

The fifth factor is teachers' assumption of professional responsibility. Professional responsibility for oneself, one's pupils, and their future is understood as a 
personal quality that is based on the ability to take responsibility for what happens to oneself and one's students and the ability to take action oriented toward preventing dangerous and extreme situations in educational institutions and toward creating healthy and safe student lifestyles using idealized models that can be specified depending on one's specialty. The development of these personal and professional qualities, as reflexive abilities and as a system of moral and ethnical values, depends on the formation of one's sense of responsibility.

The sixth factor is the formation of communicative skills that contribute to the implementation of secure interactions among individuals. At the microlevel, potential threats to social safety occur in direct communication with other people. Such threats include abuse, manipulation, and the formation of unstable social ties. The presence of such threats makes communication and related attitudes toward other people one of the leading factors. There is no doubt that what teachers say and how they say it have an impact not only on the successful assimilation of knowledge but also on health, especially mental health. Not only the teacher's speech but also communication among students themselves has an impact on students; their speech culture can negatively affect their health, especially their mental health. In the youth environment the use of foul words and profanity has been increasing dramatically. People who frequently use profanity already have defects in mental health; such speech degrades a person. In this regard, in an educational institution special attention should be directed to lamprophony, as well as to improving the speech culture of students.

The characteristic of sociability can have a negative influence on the factor of communication skills. Sociability is not a professional characteristic related to personal-confidential communication, and it can be coupled with reduced consciousness of manipulation and low critical thinking. In this case, the relevant expressions characterizing the state of information safety are "don't say anything you know, but know everything you say" and "loose lips sink ships."

\section{Conclusion}

Safety in the educational environment directly depends on the quality of the training teachers receive for developing professional competencies and personal and professional qualities that contribute to the social security of the individual in the educational environment.

Teachers' ability to provide social anticipation helps them reveal and foresee social and other dangers. Therefore, teachers should develop their watchfulness, constantly learn everything that concerns various dangers, consult specialists, and analyze their own actions and mistakes. They will then have knowledge of all the characteristics of dangers and will be able to foresee them, resolve them quickly, and eventually to avoid them. Experience in averting danger, avoiding dangerous situations, and coping with them when necessary contributes to the development of social anticipation. In the future these experiences will help teachers work out a strategy for safe behavior and they will then be able to protect themselves and the wider public from inner and outer negative factors in the environment and to provide social safety. 
The development of social tolerance in educators is part of the formation of a tolerant educational system in which an atmosphere of nonviolence is created, tolerant interactions are realized, democratic conduct is expected, and all are accepted regardless of differences in age, race, nation-ethnicity, language, property, religion, and individual-personal characteristics.

The professional orientation of a teacher toward providing social safety is a mental feature of the personality that determines the demands, motives, ideology, positions, and aims of activity in the area of social safety. A mature professionalevaluative orientation significantly contributes to the efficiency of the creative development of specialists and to the productivity of their professional work.

Teachers' abilities to have a consciously responsible attitude toward their own lives, to actively build their professional careers, and to consciously make specific choices and decisions in often unsafe situations are of particular importance in today's society. Educational space is the place where the civic and moral responsibility of the individual is accentuated. Professional responsibility is one of the regulators of pedagogical work, as a teacher has significant influence in shaping the worldview of the younger generation.

To ensure the social safety of students, teachers should possess the following communication skills and abilities:

- the ability to create personality-oriented, trust-based cooperation in the educational process, including goodwill and courtesy

- the skill of democratic communication, including the ability to listen, to understand, to convince, to explain, to argue

- the skills of speech culture, including clarity and use of literate language

- the ability to maintain emotional balance and to prevent and resolve conflicts in a constructive way, including the ability to cooperate, to reach compromise

- the ability to develop a strategy and tactics and techniques for active interaction with people, to organize joint activities for the achievement of certain societal goals

- the ability to assess the interaction of people in the education environment objectively

The psychological factors required in teachers are social anticipation, resistance to sociopsychological stress, social tolerance, professional orientation, responsibility, and communication skills; their weight and characteristics must be considered when designing a system for training teachers and as they develop their own social security as a personal-professional quality. The data from our analytical and experimental studies allowed us to determine ways to improve the organization of the educational process in order to ensure the social safety of students and society as a whole.

The relevant factors that we identified allowed us to outline a program for the formation and development of the readiness of teachers to ensure the social security of their students. The analytical study of the data revealed the necessity of implementing a complex program for creating socially safe environments in educa- 
tional institutions. The main components of our projected environment are: training teachers in special seminars how to provide social security; creating a favorable psychological climate in the classroom and school as a whole; implementing a system of social and psychological support for students and teachers; creating a tolerant educational space based on the principles of humanity and internationalism; implementing preventive measures in regard to student smoking, drinking of alcohol, and drug use.

In conclusion, it should be noted that in a changing sociocultural situation the need arises to include indicators of the social security of the individual in the educational environment in monitoring the quality of education. At the same time it is necessary to organize continuous monitoring of the state of the educational environment in order to identify social hazards and to promote the development in teachers of personally and professionally important qualities that indicate their readiness to provide social security.

\section{Acknowledgements}

Part of this study was supported by the Russian Federation President's Grant for young Russian Ph.D. researchers, No. MK-1565.2013.6.

\section{References}

Baeva, I. A. (2002). Psychological safety in education. St. Petersburg: Rech.

Dunne, M. P., Dunne, S. K., Macfarlane, B., Zolotor, A. J., Runyan, D. K., Andreva-Miller, I., ... Youssef, R. (2009). Ispcan child abuse screening tools retrospective version (ICAST-R): Delphi study and field testing in seven countries. Child Abuse \& Neglect, 33 (11), 815-825. doi: 10.1016/j.chiabu.2009.09.005

Feldshteyn, D. I. (2012). Psycho-pedagogical science as a resource of modern society. Psychological Science and Education, 1, 18-32.

Gilman, R., \& Huebner, E. (2006). Characteristics of adolescents who report very high life satisfaction. Journal of Youth and Adolescence, 35, 311-319. doi: 10.1007/s10964-006-9036-7

Glew, G. M., Fan, M-Y., Katon, W., \& Rivara, F. P. (2008). Bullying and school safety. Journal of Pediatrics, 152(1), 123-128. doi: 10.1016/j.jpeds.2007.05.045

Huebner, E., \& Gilman, R. (2006). Students who like and dislike school. Applied Quality of Life Research, 1, 139-150. doi: 10.1007/s11482-006-9001-3

Karaseva, T. V., \& Babanova, N. N. (2010). Kul'tura zdorov'ya prepodavatelya vuza [Culture of health in university lecturers]. Ivanovo.

Kislyakov, P. A., Shmeleva, E. A., Karaseva, T. V., \& Silaeva, O. A. (2014). Monitoring of education environment according to the social-psychological safety criterion. Asian Social Science, 10(17), 285-291. doi: 10.5539/ass.v10n17p285

Kislyakov, P. A., \& Silaeva, O. A. (2014). Threats of social safety of the education environment. In the World of Scientific Discoveries, 57(9.4), 1447-1458. doi: 10.12731/wsd-2014-9.4-13

Maslow, A. (2001). Motivation and personality. St. Petersburg: Eurasia.

Nansel, T. R., Overpeck, M. D., Haynie, D., Ruan, J., \& Scheldt, P. (2003). Relationships between bullying and violence among US young. Archives of Pediatrics and Adolescent Medicine, 157, 348-353. doi: 10.1001/archpedi.157.4.348

Noddings, N. (2003). Happiness and education. New York: Cambridge University Press. doi: $10.1017 / \mathrm{CBO} 9780511499920$ 
Suldo, S., Shaffer, E., \& Riley, K. (2008). A social-cognitive-behavioral model of academic predictors of adolescents' life satisfaction. School Psychology Quarterly, 23, 56-69. doi: 10.1037/1045-3830.23.1.56

Teenage cruelty in Russia turns into a profitable business. (2007). Business press, 12. Retrieved from: http://www.businesspress.ru/newspaper/article_mId_43_aId_413579.html.

Tretyakova, N. V. (2009). Osnovy organizatsii zdorov'esberegayushchey deyatel'nosti v uchebnom zavedenii [Organization of health-promoting activities in school]. Ekaterinburg.

Tucker, C. J., Finkelhor, D., Shattuck, A. M., \& Turner, H. (2013). Prevalence and correlates of sibling victimization types. Child Abuse and Neglect, 37 (4), 213-223. doi: 10.1016/j. chiabu.2013.01.006

Zinchenko, Yu. P. (2011). Security psychology as social systemic phenomenon. Psychology in Russia: State of the Art, 4, 305-315. doi: 10.11621/pir.2011.0019

Zinchenko, Yu. P., Veraksa, A. N., \& Leonov, S. V. (2011). Methodological foundations of military psychology and psychological security. Psychology in Russia: State of the Art, 4, 53-61. doi: 10.11621/pir.2011.0004

Original manuscript received July 29, 2014 Revised manuscript accepted February 03, 2015 First published online March 31, 2015 